\title{
Number sense of final year pre-service primary school teachers
}

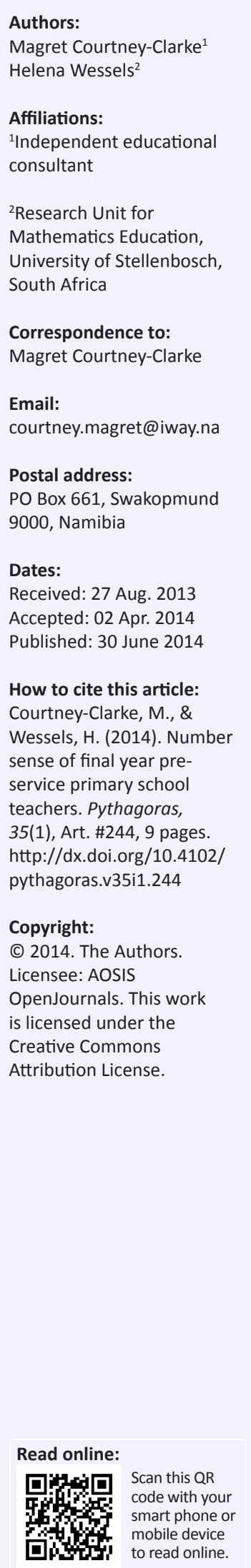

Number sense studies have indicated that the development of number sense should be the focus of primary school mathematics education. The literature review revealed that learner performance is linked to teacher subject knowledge and that teachers' confidence in doing and teaching mathematics influences the way they teach and their willingness to learn mathematics. This study was motivated by the poor performance of Namibian primary school learners in both national and international standardised assessment tests and explored the number sense of 47 final-year primary school pre-service teachers (PSTs) in Namibia. The data in this mixed method research design were obtained from a number sense questionnaire, a written computations questionnaire, a mental calculations questionnaire and the McAnallen confidence in mathematics and mathematics teaching survey (MCMMTS). Six PSTs, randomly selected from the 47 participants, were interviewed to determine their use of number-sensible strategies. The overall results of this investigation revealed that the final year primary school PSTs demonstrated limited number sense and possessed very few of the indicators of number sense. Unexpectedly, the confidence survey showed that they were confident in their ability to do and to teach mathematics. This study exposed one reason for the low standards of performance of Namibian learners in mathematics and the lack of improvement over the last few decades. It indicates a need for teacher training institutions to identify the mathematics that teachers should know and the ways in which teacher understanding of subject content has to be transformed to enable them to develop the number sense of primary school learners.

\section{Introduction}

The skills and dispositions to make sense of numerical situations in everyday life underpin the ability to understand, critically respond to and use mathematics in different social, cultural and work contexts. These skills and dispositions are related to number sense, which is increasingly seen as an important outcome of primary school mathematics education in the 21st century.

The term 'number sense' reflects the changes in the perception of the role and nature of arithmetic in primary school mathematics. People with number sense have a disposition to make sense of numerical situations, look at problems holistically and use numbers flexibly to do mental calculations, produce reasonable estimates of numerical quantities and use figures to support an argument (Sowder \& Schappelle, 1989).

This study explored the likelihood that the lack of number sense of primary school teachers might be a related to the poor performance of Namibian primary school learners in both national and international standardised assessment tests.

\section{The Namibian context}

In Namibia, the identified skills shortage fields in the professional careers (e.g. engineers and accountants), the technical careers (e.g. computer technicians) and the trade careers (e.g. electricians) require appropriate numeracy skills or a high level of mathematical proficiency (Links, 2010). However, educational statistics reveal both a shortage of Grade 12 graduates with higher-level mathematics and low numeracy levels at the end of primary school. In 2012, only 3\% of Grade 12 mathematics enrolments were at higher level (Directorate of National Examinations and Assessment, 2013); the Grade 5 and Grade 7 standardised achievement test results showed that most of the participating learners performed in the below-basic and basic categories (Kavishe, 2013). Spaull (2011) classified 53\% (adjusted for dropout rates) of Namibian Grade 6 students as functionally innumerate based on the 2007 Southern and Eastern Africa Consortium for Monitoring Educational Quality III results.

Both Kavishe (2013) and Spaull (2011) linked low primary school learner performance to poor mathematics teacher competence. The Grade 6 mathematics teachers' average score was below 
the Southern and Eastern Africa Consortium for Monitoring Educational Quality average learner score (Spaull, 2011) and the standardised achievement test results suggest that teachers were challenged in delivering in the standardised achievement test competency areas (Kavishe, 2013). This indicates that mathematics education in Namibian primary schools is largely ineffective in developing the basic numeracy skills required for further studies in mathematics. Mathematics teaching in Namibian primary school classrooms is still characterised by drill, practice and rote learning (Clegg \& Courtney-Clarke, 2009). Mathematics PSTs are a product of how and what they were taught in schools and will, without an appropriate education at tertiary level, carry the same practices forward to their own teaching at school.

\section{Number sense}

The notion of number sense embodies the most important concepts, skills and attitudes that learners should acquire in primary school as a foundation for further studies in mathematics and the development of quantitative literacy. Number sense is complex and can best be described by the skills and understandings that a person with number sense demonstrates: a concrete sense of quantity, including multi-digit whole numbers, fractions and decimals and their different representations, an understanding of the relative magnitude of an amount, an ability to compare quantities using benchmark numbers such as $0, \frac{1}{2}$ or 100 , automatic recall of basic facts, procedures and strategies and the application of this knowledge to operations and to solve problems, flexibility in performing mental calculations and the ability to judge the reasonableness of an answer.

McIntosh, Reys and Reys (1992) define number sense as

a person's general understanding of number and operations along with the ability and inclination to use this understanding in flexible ways to make mathematical judgements and to develop useful strategies for handling number and operations. (p. 3)

A firm understanding of numbers and the number system is central to learning mathematics (Hiebert, Carpenter \& Moser, 1982; Sowder \& Wheeler, 1989). Reys, Reys, McIntosh, Emanuelsson and Yang (1999) in their study of the number sense of learners concluded that 'it was the consistently low performance of students across all countries that reminded us of the common international challenge this topic provides' (p. 68).

Mathematical activity is present in all cultures, even without formal schooling; Dehaene (2001) hypothesises from a cognitive neuroscience perspective that number sense qualifies for a biologically determined category of knowledge. His hypothesis is based on studies of the brain as well as experiments with animals and infants to establish basic numerosity:

I propose that the foundations of arithmetic lie in our ability to mentally represent and manipulate numerosities on a mental 'number line', an analogical representation of number; and that this representation has a long evolutionary history and a specific cerebral substrate as single, analog representation. (Dehaene, 2001, p. 17)

Dehaene's theory of an evolutionary, biological base of number sense fits observations about the intuitive understanding of numbers and counting of children under the age of six (Jordan, 2007).

It is through development and education that this central representation becomes connected to other cognitive systems and conceptual structures, which need to be internalised and coordinated. Case (1989) observed that the degree of number sense varies between individuals, groups and cultures and is influenced by the type and amount of mathematical activity in which young children engage.

\section{The development of number sense and the role of the teacher}

Children who lack a sound foundation for mathematical understanding will experience difficulties with mathematics in later years and this will become ever more difficult to remediate as time passes (Chard et al., 2008). Intervention programs have demonstrated that instruction including number sense activities, with focus on mental computation or estimation, can improve mathematics performance significantly (Gersten, Jordan \& Flojo, 2005; Gersten \& Chard, 1999; Hing, 2007; Jordan, 2007; Markovits \& Sowder, 1994).

Conceptual understanding as a foundational aspect of number sense is highlighted in the definition of number sense as 'a well-organised conceptual network of number information that enables one to relate numbers and operations to solve problems in flexible and creative ways' (Markovits \& Sowder, 1994, p. 23). Teaching for number sense should therefore focus on learners and their solution strategies rather than on the right answers, on thinking rather than the mechanical application of rules and on learner-generated solutions rather than on teacher-supplied answers (Reys et al., 1992). This is very challenging for teachers who, like the teachers in Namibia, have traditionally emphasised mastery of algorithms and repeated practice with little focus on conceptual understanding of mathematics concepts, which includes the understanding of numbers and the number system.

Children who do not grow up in an environment that exposes them early to quantitative thinking and analysis will not acquire number sense without formal explicit instruction. These include children from low-income families, minority groups, children from homes where both parents work, nonEnglish speakers and children living in poverty (Gersten et al., 2005). In Namibia, early interventions and formal explicit instruction that is aimed at developing number sense might have to be geared towards the entire system as children in developing countries 'are frequently at the same levels as children who in the developed world are seen as needing special help' (Reubens, 2009, p. 2). 
This puts the spotlight on the teachers and their competence to develop learners' number sense. Teachers should be confident in their knowledge and understanding of how the number system works, be able to use this understanding in flexible ways to make mathematical judgements and have a repertoire of strategies for handling numbers and operations (National Council of Teachers of Mathematics, 1991); this means that teachers should possess number sense themselves.

This argument is supported by other researchers. Ma (1999) compared a teacher to a guide who takes learners from their current understanding to further learning and prepares them for future travel. To be able to do this, the teacher needs a sound understanding of the key mathematical concepts for the learners' grade level as well as an understanding of how those concepts connect with learners' prior and future learning. Such knowledge includes an understanding of the 'conceptual structure and basic attitudes of mathematics inherent in the elementary curriculum' (Ma, 1999, p. xxiv) as well as an understanding of how best to teach the concepts to children. This is what Ball, Thames and Phelps (2008) termed specialised content knowledge, an 'uncanny kind of unpacking mathematics' (p. 400) that makes particular features of content visible to and learnable by all children. Trafton (1989) indicates that number sense should not be treated as a new topic, but rather that 'number sense needs to be an ongoing, informal emphasis in all work with numbers' (p. 75). This is reflected in the notion of big ideas, which are statements that focus on mathematical ideas as networks of interrelated concepts so that 'mathematics can be represented as coherent and connected enterprise' (National Council of Teachers of Mathematics, 2000, p. 17). For example, one big idea for early number sense is 'numbers are related by a variety of number relationships'.

Hill (2008), in a study that explored the relationship between teacher subject matter knowledge and instruction, came to the 'inescapable conclusion ... that there is a powerful relationship between what a teacher knows, how she knows it, and what she can do in the context of instruction' (p. 497).

Researchers into the number sense of teachers in various countries, for example Australia (Kaminski, 1997), the United States (Johnson, 1998 in Tsao, 2005), Taiwan (Tsao, 2004, 2005; Yang, Reys \& Reys, 2009) and Kuwait (Alajmi \& Reys, 2007) have concluded that the majority of primary school teachers have limited number sense and very little understanding of what number sense is. For example, teachers tend to rely on standard algorithms and avoid mental calculations and estimation; they do not use benchmarks to reason about the effects of operations; they cannot flexibly apply numbers and operations to computational situations; they hold some of the same misconceptions as their learners, especially in the domain of rational numbers. If we want to improve learners' number sense, the development of number sense should become a focus of pre-service primary school teacher education (Yang et al., 2009)
However, not only content knowledge and skills play an important role. Teachers' self-confidence affects the way in which they approach problems, the connections they are able to make between related concepts and their repertoires of strategies (Ball, 1990). Graven (2004) hypothesises that confidence in being able to learn mathematics is a resource that enables teachers with little mathematics training to learn the mathematical competencies required for teaching mathematics. Attempts to improve PSTs' content knowledge should therefore be coupled with a safe and supportive environment in which these students can develop confidence and positive feelings towards the subject.

One cannot develop number sense in others if one does not possess a certain measure of number sense oneself; this was aptly put by Greeno (1991) who stated that if someone 'is to serve as an effective guide to newcomers in an environment, it is essential that the guide himself or herself should be a comfortable resident of the environment' (p. 55).

\section{Theoretical framework}

More recently, the focus has shifted to defining number sense in terms of its characteristics as summarised by Kalchman, Moss and Case (2001): fluency in estimating and judging magnitude, the ability to recognise unreasonable results, flexibility when mentally computing, the ability to move amongst different representations and to use the most appropriate representations and the ability to represent the same number or function in multiple ways depending on the context or purpose of this representation.

In this study the characteristics of number sense were regarded within the framework of 'mathematical proficiency'. According to Kilpatrick, Swafford and Findell (2001), mathematical proficiency has five strands:

Conceptual understanding refers to an integrated and functional grasp of mathematics. Conceptual understanding is reflected in the ability to represent mathematical situations in different ways and to apply the most useful representations in different situations.

Procedural fluency refers to the knowledge of procedures, when and how to use them and the skill in performing them flexibly, accurately and efficiently. It also includes the knowledge of ways to estimate the results of a procedure. Rapid, automatic access to facts and procedures enables a learner to pay attention to the interrelationship between concepts.

Strategic competence refers to the ability to formulate, represent and solve mathematical problems. Proficient problemsolvers are flexible in their approach to solving non-routine problems, form mental representations of problems, detect mathematical relationships and devise new solution methods where needed. Strategic competence allows flexibility in performing mental calculations. 
Adaptive reasoning refers to the capacity for logical thought, reflection, explanation and justification: 'In mathematics, adaptive reasoning is the glue that holds everything together, the lodestar that guides learning' (Kilpatrick et al., 2001, p. 129). Adaptive reasoning includes informal explanation and justification and intuitive and inductive reasoning based on pattern, analogy and metaphor. Adaptive expertise requires an understanding of how and what procedures work and how these can be modified to fit the constraints of a problem. It requires the ability to deal with a problem holistically, to know what to do without the need to articulate a procedure before beginning and to monitor and regulate the process of problem-solving.

Productive disposition is a tendency to see mathematics as sensible, useful and worthwhile and seeing oneself as capable to learn, understand and do mathematics.

These strands are not independent; they represent different aspects of a complex whole and have to be developed together. This is exemplified by proficiency in estimation and mental calculations, important indicators of number sense. Kilpatrick et al. (2001, p. 215) argue that computational estimation integrates all strands of mathematical proficiency. It requires a flexibility of calculation that emphasises adaptive reasoning and strategic competence, guided by a person's conceptual understanding of both the problem situation and the mathematics underlying the calculation and fluency with computational procedures. Good estimators rely on mental calculations to find an approximate but satisfactory answer. They demonstrate a deep understanding of numbers and operations; they are flexible in their thinking and use a variety of strategies when solving problems. A disposition to make sense of a situation to produce reasonable answers instead of wild guesses is a prerequisite of competent estimators.

Mental calculation and estimations skills should be developed continuously throughout the primary school years and beyond in order for number sense to develop. To become proficient, learners need 'to spend sustained periods of time doing mathematics - solving problems, reasoning, developing understanding, practicing skills - and building connections between their previous knowledge and new knowledge' (Kilpatrick et al., 2001, p. 133).

\section{Research design}

The focus of this project (Courtney-Clarke, 2012) was to explore the skills, knowledge, strategies and confidence related to number sense of Namibian final year pre-service primary school teachers.

In this study a concurrent mixed methods design was used. Questionnaires and tests were administered to collect quantitative data on pre-service primary school teachers' number sense. Concurrent with this data, qualitative data was collected through semi-structured interviews. The role of the qualitative data was to clarify and understand the quantitative data. The results of the two methods were integrated in the interpretive phase.
Number sense is an elusive construct and its operationalisation requires the expertise of an experienced professional researcher. The number sense questionnaire, mental calculations questionnaire and the written computation questionnaire were based on instruments developed by Yang in 1997 (Reys \& Yang, 1998). According to Yang (in Hing, 2007), the split-half reliability of the number sense test is over 0.80 for both Grade 6 and Grade 8 learners and the Cronbach's alpha reliability coefficient is 0.80 . Yang's number sense test has been used in research with both learners and teachers (Alajmi \& Reys, 2007; Hing, 2007; Reys et al., 1999, Reys \& Yang, 1998; Tsao, 2004, 2005) and in the absence of similar reliable instruments of southern African origin, we opted for using Yang's tests.

Some of the selected items were adapted to make them more accessible to the expected competency levels of Namibian primary school teachers in the following ways:

- The whole number range was reduced to numbers less than 10000 (e.g. $9135 \div 61$ instead of the original $913582 \div 6183)$.

- The number of questions in the whole number domain was increased by changing decimals to whole numbers (e.g. the lengths of strings measuring $54.125 \mathrm{~m}$ and $29.85 \mathrm{~m}$ in the original question, were changed to $541 \mathrm{~m}$ and $298 \mathrm{~m}$ respectively).

- Contexts, such as names and units, were localised (e.g. 'Wang' and 'Lin' were replaced by 'Sarah' and 'Leonard' and cubic feet were changed to litres).

The reliability of the adapted tests was not established.

The number sense questionnaire was central to the research. The 27 selected items reflected the strands of number sense as a mathematical proficiency, namely the conceptual understanding of order, properties and representations of numbers, procedural fluency in calculating and in estimating and judging magnitude, strategic competence in carrying out mental calculations and detecting mathematical relationships, adaptive reasoning in recognising unreasonable results and in representing the same number or function in multiple ways depending on the context or purpose of this representation.

The McAnallen confidence in mathematics and mathematics teaching survey (MCMMTS) (McAnallen, 2010) was used to determine whether the PSTs were confident in their ability to understand, do and teach mathematics, that is whether they possessed a productive disposition towards mathematics. The survey consists of 25 items, 12 relating to personal selfefficacy and anxiety (Factor 1 ) and 13 relating to teaching selfefficacy and anxiety (Factor 2). The reliability analysis of the MCMMTS (McAnallen, 2010) yielded the following: Factor 1 (personal mathematics self-efficacy and anxiety factor) had a Cronbach's alpha of 0.923 and Factor 2 (teaching self-efficacy and anxiety factor) had a Cronbach's alpha of 0.952. Certain words and phrases were replaced with terminology used in the Namibian context (e.g. the word 'student' was replaced with 'learner'). 
To triangulate and validate the findings from the quantitative data, a semi-structured interview schedule was used to investigate what understandings, procedures, strategies and reasoning the students used in answering six questions selected from the number sense questionnaire. All the interviews were transcribed from the audiotape and the results coded into four categories: initial answers, approaches (rule-based or number-sense based), language use and confidence.

The research was conducted with 47 final-year lower primary and upper primary mathematics PSTs enrolled at a university education campus in Namibia that attracts students from all regions of the country. The use of purposive sampling of the total number of primary pre-service students was based on considerations of expense, time and accessibility.

To increase the reliability and validity of the adapted instruments and the semi-structured interview a pilot study was conducted with local lower primary teachers. The pilot study proved to be essential in refining the instruments and the data collection process, for example by changing some unfamiliar phrases, adding practice examples and timing the mental calculation questions through the use of a PowerPoint presentation.

The data analysis followed the path of the concurrent triangulation model. The data from the four quantitative instruments were analysed using the predictive analysis software (SPSS, 2009). Descriptive statistics (mean, median, standard deviation and graphical representations) were obtained for the number sense questionnaire, the written computations questionnaire and the mental calculations questionnaire. Correlation analysis was performed on the results to establish a possible relationship between the student's written computation and mental calculation skills and their number sense and their confidence in mathematics and mathematics teaching and their number sense.

\section{Ethical considerations}

This investigation was compliant with all ethical requirements set by the tertiary institution where the project was registered. Approval for the research was obtained from the tertiary institution where the data were collected. Participation was voluntary and information about the project was shared with participating PSTs. The commitment to keep all results confidential and report on the research and findings anonymously was communicated to all participants.

\section{Findings}

In analysis of the collected data, five main findings, based on the theoretical framework of mathematical proficiency, arose.

\section{Conceptual understanding}

The analysis of performance on the three number domains of whole numbers, common fractions and decimal fractions
(Table 1) showed that the primary PSTs are more competent and comfortable working with whole numbers than with either common fractions or decimal fractions. Performance on the common fractions domain was particularly poor on the number sense and the mental calculations questionnaires. However, some PSTs were proficient in applying paper-andpencil methods to calculations with fractions as the standard deviation of $29 \%$ on the written computations questionnaire shows.

These results were reflected in the mean of $22.7 \%$ obtained in the number sense domain 'Knowledge of and facility with numbers' and in the interview data for this domain.

We illustrate the main findings with a few examples:

1. Only $32 \%$ of the respondents could spot the incorrect number sequence in Question 17, which tested the knowledge of orderliness of whole numbers.

Which of the following number sequences is wrong?

$\begin{array}{lll}\text { A. } 3000 ; 3500 ; 4000 ; 4500 & \text { B. } 7600 ; 7700 ; 7800 ; 7900\end{array}$

C. $6097 ; 6098 ; 6099 ; 7000$ D. $8080 ; 8090 ; 8100 ; 8110$

2. In Question 20, less than half the PSTs could find the fraction that was represented by the shaded area. This question involved multiple representations of fractions on two levels: finding the correct part of the whole and then simplifying the answer.

Find the fraction that represents the shaded area

A. $\frac{3}{5}$ B. $\frac{4}{12}$ C. $\frac{5}{16}$ D. $\frac{3}{8}$ E. $\frac{6}{15}$

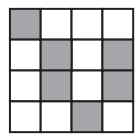

3. Question 5 required the recognition of the relative size of common fractions and was answered correctly by $25 \%$ of the PSTs.

$$
\text { Is } \frac{3}{8} \text { or } \frac{7}{13} \text { closer to } \frac{1}{2} \text { ? Why? }
$$

Question 5 was included in the interview with six randomly selected students. All of the respondents found this question challenging; as one of them put it, 'A very tricky one'. Only one chose the correct answer, and went on to explain her reasoning:

'Because ... mmm ... you divide the two ... the one into the seven will be a remainder, but if I take the first expression, then the three can go into the eight like two times ... that will be less than one over eight ... that will be bigger than seven over ...'.

TABLE 1: Descriptive statistics for the number sense questionnaire, written computation questionnaire and mental calculations questionnaire by number domain (\%).

\begin{tabular}{llccc}
\hline $\begin{array}{l}\text { Questionnaire } \\
(\boldsymbol{N = 4 7 )}\end{array}$ & Statistic & $\begin{array}{c}\text { Whole } \\
\text { numbers }\end{array}$ & $\begin{array}{c}\text { Common } \\
\text { fractions }\end{array}$ & Decimals \\
\hline Number sense & Mean & 49.4 & 22.3 & 41.8 \\
& SD & 17.5 & 12.1 & 17.5 \\
Written computation & Mean & 52.8 & 35.5 & 28.7 \\
& SD & 24.8 & 29.0 & 22.1 \\
Mental calculations & Mean & 25.5 & 19.1 & 23.8 \\
& SD & 19.4 & 17.0 & 20.7 \\
\hline
\end{tabular}

$N$, number. 
This attempted explanation is an example of the difficulty the PSTs had in verbalising their thinking and their understanding, pointing to a lack of deep conceptual understanding of the mathematics that they have to teach.

\section{Procedural fluency}

Despite the focus in Namibian schools on the application of procedures and standard algorithms to obtain a correct answer, the mean of the written computation questionnaire was only $39.3 \%$. However, a high standard deviation of $18 \%$ indicated that some PSTs were competent in performing written computations.

The analysis of the performance of the four operations in the written computation and the mental calculations questionnaires (Table 2) showed that the PSTs are more competent in performing addition and subtraction than multiplication and division. Performance on division was particularly poor with a mean of $18.1 \%$ on the written computation questionnaire and $10.6 \%$ on the mental calculations questionnaire.

The Pearson correlation coefficient of $r=0.457, p<0.01$ (twotailed) between the two questionnaires was substantial and positive, indicating than there is a significant relationship between written and mental calculation proficiency.

The analysis of the written computation questionnaire and interview data shed more light on this relationship as the following examples illustrate:

1. The preferred method in the written computation questionnaire to answer the question $995+872+838+$ 809 was step-wise column addition, that is adding the first two numbers, then the third to the answer, and so on. This indicated that PSTs were not confident in their ability to mentally add four one-digit numbers correctly.

2. Only 11 PSTs arrived at the correct answer to the question: Find the value of $\square$, if $45 \times \square=2700$.

Most attempted to solve the problem by repeated addition: $45+45=90 ; 90+45=135$, but failed to keep track of the addition and left the question uncompleted.

It was inferred from both the quantitative and the qualitative data that many PSTs were not fluent in their basic facts knowledge and weak in their application of standard procedures in the rational number domain.

\section{Strategic competence}

The very poor performance on the mental calculations questionnaire with a mean of $23 \%$ and standard deviation of
$15 \%$ indicated that PSTs demonstrated a low proficiency to calculate mentally at a Grade 6 level. Figure 1 illustrates the performance on the different number domains.

Mental calculations require a combination of memory of basic facts and strategies (Kilpatrick et al., 2001), that is a combination of procedural fluency and conceptual understanding. The poor performance in the whole number domain on the mental calculations questionnaire indicated that the PSTs lacked basic facts knowledge and strategic competence to calculate mentally.

Some examples are:

1. Only six out of the 47 PSTs found the correct answer to $232-98$. This indicated that the majority were trying to work this out by mental application of the algorithm, which is difficult because if it involves 'borrowing'. The 'count-up' strategy would have yielded the correct answer very quickly: $98+2+132=232$.

2. $512 \div 4$ received one correct answer. The preferred strategy of repeated addition of 4 would indeed take a very, very long time. Here application of the fact that $4 \times 25=100$ would have been one possible efficient strategy.

3. $36 \times 50$ was answered correctly by only two PSTs. Perhaps some PSTs tried to add 50 thirty-six times; others might have tried to do long multiplication mentally. The obvious strategy here would have been to multiply by 100 and then divide by 2 .

4. $4 \times 3 \frac{1}{2}$ was answered correctly by four PSTs. The correct answer could have been obtained simply by 'double and double again'.

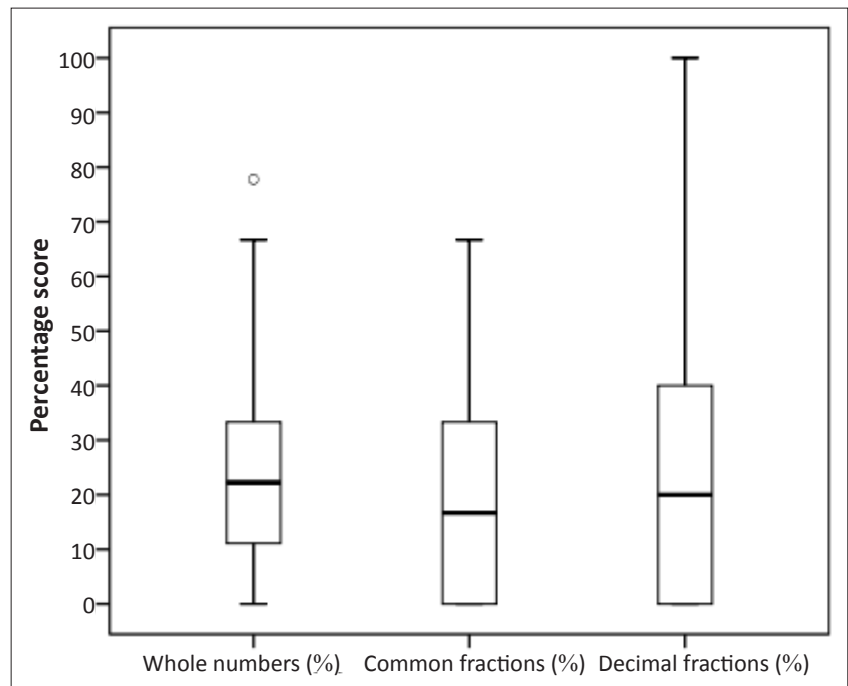

FIGURE 1: Distribution of scores for the three number domains on the menta calculations questionnaire.

TABLE 2: Descriptive statistics for the written computation and mental calculations questionnaires by operation (percentages).

\begin{tabular}{|c|c|c|c|c|c|}
\hline Questionnaire $(N=47)$ & Statistic & Addition & Subtraction & Multiplication & Division \\
\hline \multirow[t]{2}{*}{ Written computation } & Mean & 52.5 & 49.5 & 37.6 & 18.1 \\
\hline & SD & 24.9 & 30.2 & 24.7 & 20.7 \\
\hline \multirow[t]{2}{*}{ Mental calculations } & Mean & 35.5 & 29.3 & 15.2 & 10.6 \\
\hline & SD & 21.0 & 25.2 & 15.9 & 17.9 \\
\hline
\end{tabular}

$N$, number. 
The interview data showed that the respondents relied on the mental application of an algorithm to work out the answer to $541-298$ and admitted that the size of the numbers made it difficult to find the answer to the subtraction question mentally. The problem 'How many minibuses will be needed to transport 170 learners, if one minibus can transport 15 people?' was solved by repeated addition of 15: 'I did like fifteen, fifteen, fifteen, fifteen, fifteen ... then I go thirty, thirty.' Number sense-based strategies of estimation and mental calculations were not available to the respondents.

The lack of number sense-based strategies coupled with the lack of conceptual understanding and basic facts fluency made the mental calculations questionnaire very challenging for the PSTs.

The correlation between the mental calculations questionnaire and the number sense questionnaire of 0.540 , $p<0.01$ (two-tailed), indicated that the relationship between mental calculation and number sense is positive, substantial and significant, supporting the claim that mental calculations and number sense develop together and 'one cannot exist without the other' (Griffin, 2003, p. 306).

\section{Adaptive reasoning}

Estimation is regarded as an indicator of number sense. It requires knowledge of place value, basic facts and properties of operations as well as an ability to compare numbers by size, compute mentally and work with powers of ten (Sowder \& Wheeler, 1989). Tsao (2005) found that pre-service primary school teachers in his study felt uncomfortable providing estimates. This may be true for Namibian PSTs as well: the overall mean for the 13 estimation questions on the number sense questionnaire was only $40 \%$.

Table 3 shows an analysis of the 13 estimation questions by number domain and operations.

Estimation skills were apparent in questions where rounding small whole numbers to add or subtract was appropriate, but not in questions involving multiplication and division or rational numbers. This was confirmed during the interviews.

\section{Some examples are:}

1. Not a single respondent used estimation to place the decimal comma in the multiplication problem 'Place the decimal comma in the calculation 534,6 $\times 0,545=291357$ '. Of the three respondents who obtained the correct answer, one could not give a reason and the other two used the rule for addition of decimal numbers by rewriting the

TABLE 3: Analysis of estimation questions on the number sense questionnaire.

\begin{tabular}{llc}
\hline Estimation questions & Number domain and operation & Mean \\
\hline Q2, Q3, Q9 & $\begin{array}{l}\text { Addition or subtraction of two whole } \\
\text { numbers smaller than 100, or decimals }\end{array}$ & $73 \%$ \\
Q1, Q4, Q13, Q14, Q22 & $\begin{array}{l}\text { Addition of more than two whole } \\
\text { numbers greater than 100, } \\
\text { multiplication and division of whole } \\
\text { numbers or decimals }\end{array}$ & $40 \%$ \\
Q6, Q7, Q8, Q11, Q12 & \begin{tabular}{l} 
Operations on common fractions \\
\hline
\end{tabular} & $20 \%$ \\
\hline
\end{tabular}

question in column form, aligning the decimal commas. An incorrect answer of 29,1375 was arrived at by using the rule for multiplication of decimals, but then not reflecting upon or questioning the reasonableness of the answer.

2. When asked 'A minibus can transport 15 people. How many minibuses would you need to transport 170 learners?', answers of ' 5 ', ' 6 ' and even ' 16 ' were given. These were guesses more than justified estimates. Not a single respondent made use of the number fact $10 \times 15=150$ to arrive at a reasonable estimate.

\section{Productive disposition}

The Pearson correlation coefficients between the total scores on the number sense questionnaire and the total scores obtained on the McAnallen confidence in mathematics and mathematics teaching survey overall, Factor 1 and Factor 2, were all positive, substantial and significant, namely $r=0.553, p<0.01 ; r=0.478, p<0.01$ and $r=0.502, p<0.01$ respectively. This indicates the PSTs with greater confidence in their ability to do and their ability to teach mathematics also displayed a greater degree of number sense.

Despite the poor performance on all the tests and the demonstration of a lack of confidence in answering number sense questions during the interviews, the PSTs were very confident in both their ability to do mathematics (Factor 1 ) and in their ability to teach mathematics (Factor 2) with an overall mean score of 3.78 out of a possible score of 5 . This result was both surprising and disturbing, because this investigation revealed that both the PSTs' language competence and subject matter knowledge were insufficient for effective teaching of mathematical concepts and procedures.

The test results did not demonstrate the PSTs ability to do mathematics; however, the mean score on Factor 1 was 3.57. We would like to put forward two conjectures: firstly, that the confidence that the PSTs displayed in their ability to do mathematics was, in their minds, not linked to the performance on the questionnaires, but to their performance in their university mathematics course. Secondly, and more worryingly, these primary PSTs might exhibit confidence in their own incorrect knowledge.

The mean for Factor 2, confidence in the ability to teach mathematics, was 3.97 - substantially higher than the mean for Factor 1. Possibly the PSTs with their lack of classroom experience, assume that anyone who has completed secondary school mathematics is competent to teach at lower primary level and that teaching mathematics consists of explaining sets of rules and procedures. More research is needed to find an explanation for these contradictory findings.

\section{Discussion}

The overall results of this study revealed that the final year primary PSTs demonstrated limited number sense and possessed very few of the indicators of number sense as a 
mathematical proficiency. The absence of deep conceptual understanding was demonstrated by their inability to move amongst different representations of numbers, to recognise the absolute and relative values of numbers and to explain their thinking. They lacked procedural fluency particularly in the domain of rational numbers and the operations of multiplication and division. They had little or no access to a variety of flexible strategies to solve problems and calculate mentally. They showed a tendency to guess answers, instead of arriving at estimates through reasoning and reflection and paid little attention to unreasonable results. Although the interviewed respondents demonstrated a lack of confidence, the confidence survey showed that these primary PSTs judged themselves as capable to learn, understand, do and teach mathematics.

During the interviews respondents had to explain their answers. One must wonder whether primary school learners would be able to follow the often confused and incoherent explanations. Apart from language problems, the respondents' struggle to explain and reason indicated that they lacked conceptual understanding, which is a prerequisite for number sense. However, they could recall rules or algorithms reasonably fluently, if not always correctly. This concurs with the Taiwanese studies by Tsao (2005), who found that only high ability students demonstrated the use of number sense characteristics in their explanations, and Yang et al. (2009), whose study showed that less than one-third of the 280 PSTs used components of number sense to explain their answers.

Although the mean on the number sense questionnaire of 38.1\% indicates that Namibian primary PSTs' performance on the number sense questionnaire was poor compared to that found in similar international studies (Tsao, 2004, 2005), the Namibian teachers are not an exception. As Yang et al. (2009) concluded,

breaking the shackles of rotely applying algorithms and promoting greater development and application of number sense components in mathematical problem solving is an international challenge. (p. 400)

Developing number sense as a mathematical proficiency implies a shift away from teaching a collection of procedures and rules to developing a mathematical disposition that engages children at an early age in mathematical thinking and on laying the foundation for learning concepts that are more advanced. This study has revealed that the PSTs do not have the specialised content knowledge (Ball, 1990) to serve as 'guides' in the environment of numbers and operations. Indeed, there were indications that they also lack common content knowledge as their inability to use basic facts and procedures fluently in written computations showed.

However, the research showed that the primary PSTs are confident in both their ability to learn and to teach mathematics. This indication of a productive disposition is a resource that enables teachers to learn the mathematical competences required to teach mathematics (Graven, 2004) and may be a way forward to move Namibian teachers from teaching procedures to teaching conceptually and developing number sense, both their own and that of the learners.

Although the findings were limited to a sample of only 47 final-year PSTs of one university campus and cannot be generalised across all teacher training or similar institutions, similar shortcomings in in-service primary mathematics teacher knowledge and its implications were identified in the reports reviewed in the introduction.

More research is needed in the field of mathematics education in Namibia, possibly in collaboration with other southern African countries that experience similar problems. The mathematics education departments at teacher training institutions should research and identify the mathematics that teachers need to know and the ways in which teacher understanding of subject content needs to be transformed so that they can teach children to develop mathematical proficiency. Academic language proficiencies required for mathematics teaching to ensure that conceptual and procedural discourse can take root in primary school classrooms should form part of this research.

\section{Conclusion}

The mathematical proficiency characterised by conceptual understanding, procedural fluency, strategic competence and adaptive reasoning in the domain of numbers and operations forms the fundamental building block of the entire mathematics curriculum (Kilpatrick et al., 2001). This study has shown that the final year primary PSTs are not proficient in number sense themselves and are therefore ill-equipped to promote number sense in the learners that they will teach. In addition, we may infer that many in-service teachers do not possess the knowledge, skills and understanding to implement a focus on number sense.

The lack of a sound foundation in the domain of numbers and operations may be the root cause of the low standards of performance of Namibian learners in mathematics at all levels and the lack of improvement over the last decade or more.

This leads to the conclusion that teacher training institutions need to re-assess the mathematics education curriculum and include programmes to develop the number sense of PSTs.

This investigation has explored broad issues around number sense. It should serve as a starting point for mathematics educators to discuss the challenges of developing a numerate society in Namibia.

\section{Acknowledgements}

The authors are grateful to Professor Der-Ching Yang and Dr Rachel McAnallen for providing us with the number sense tests and the McAnallen confidence in mathematics and mathematics teaching survey respectively and their 
permission to use and adapt their instruments for the purposes of this research.

\section{Competing interests}

The authors declare that they have no financial or personal relationship(s) that may have inappropriately influenced them in writing this article.

\section{Authors' contributions}

The article presents the results of a study in which M.C.-C. conducted the research whilst H.W. (University of Stellenbosch) supervised the study. The article was planned together. M.C.-C. wrote the manuscript and H.W. made conceptual and editorial contributions.

\section{References}

Alajmi, A., \& Reys, R. (2007). Reasonable and reasonableness of answers: Kuwait middle school teachers' perspectives. Educational Studies in Mathematics, 65, 77-94. http://dx.doi.org/10.1007/s10649-006-9042-4

Ball, D.L. (1990). The mathematical understandings that prospective teachers bring to teacher education. The Elementary School Journal, 90(4), 449-466. http://dx.doi. org/10.1086/461626

Ball, D.L., Thames, M. H., \& Phelps, G. (2008). Content knowledge for teaching: What makes it special? Journal of Teacher Education, 59(5), 389-407. http://dx.doi. org/10.1177/0022487108324554

Case, R. (1989). Fostering the development of children's number sense: Reflections on the conference. In J. Sowder, \& B. Schappelle (Eds.), Establishing foundations for research on number sense and related topics: Report of a conference (pp. 57-64). San Diego, CA: San Diego State University.

Chard, D.J., Baker, S.K., Clarke, B., Jungjohann, K., Davis, K., \& Smolkowsi, K. (2008) Preventing early mathematics difficulties: The feasibility of a rigorous mathematics curriculum. Learning Disability Quarterly, 31, 11-20.

Clegg, A., \& Courtney-Clarke, M. (2009). Consultancy to develop a strategic plan to strengthen the content knowledge, skills and methodology of mathematics to strengthen the content knowledge, skills and methodology of mathematics
teachers at primary and secondary schools in Namibia. Report submitted teachers at primary and secondary schools in Namibia. Report submitted
to the Ministry of Education. Available from http://xa.yimg.com/kq/ to the Ministry of Education. Available from http://xa.yimg
groups/21575095/2016540364/name/MathsReportCompressedv1.pdf

Courtney-Clarke, M. (2012). Exploring the number sense of final year primary preservice teachers. Unpublished master's dissertation. University of Stellenbosch, service teachers. Unpublished master's dissertation. University of Stellenbosch,
Stellenbosch, South Africa. Available from http://hdl.handle.net/10019.1/19943

Dehaene, S. (2001). A précis of number sense. Mind \& Language, 16(1), 16-36. http:// dx.doi.org/10.1111/1468-0017.00154

Directorate of National Examinations and Assessment. (2013). Statistics of the Oct/ Nov 2012 national examinations. Windhoek: DNEA.

Gersten, R., \& Chard, D.J. (1999). Number sense: Rethinking arithmetic instruction for students with mathematical disabilities. LD OnLine. Available from http://www. Idonline.org/article/5838

Gersten, R., Jordan, N.C., \& Flojo, J.R. (2005). Early identification and interventions for students with mathematics difficulties. Journal of Learning Disabilities, 38(4), 293-304. http://dx.doi.org/10.1177/00222194050380040301

Graven, M. (2004). Investigating mathematics teacher learning within an inservice community of practice: The centrality of confidence. Educational
Studies in Mathematics, 57, 177-211. http://dx.doi.org/10.1023/ Studies in Mathematics,
B:EDUC.0000049277.40453.4b

Greeno J.G. (1991). Number sense as situated knowing in a conceptual domain Journal for Research in Mathematics Education, 22(3), 170-218. http://dx.doi. Journal for Research
org/10.2307/749074

Griffin, S. (2003). Laying the foundation for computational fluency in early childhood. Teaching Children Mathematics, 9(6), 306-311.

Hiebert, J., Carpenter, T., \& Moser, J. (1982). Cognitive development and children's solutions to verbal arithmetic problems. Journal for Research in Mathematics Education, 13, 83-98. http://dx.doi.org/10.2307/748356

Hill, H.C. (2008). Mathematical knowledge for teaching and the mathematical quality of instruction: An exploratory study. Cognition and Instruction, 26, 430-511. http://dx.doi.org/10.1080/07370000802177235
Hing, L.Y. (2007). The relationship between numerical estimation and number sense in students' learning of mathematics. Unpublished master's thesis. The University of Hong Kong, Pokfulam, Hong Kong. http://dx.doi.org/10.5353/th_b4004017

Jordan, N.C. (2007). Predicting first-grade math achievement from developmental number sense trajectories. Learning Disabilities Research \& Practice, 22(1), 3646. http://dx.doi.org/10.1111/j.1540-5826.2007.00229.x

Kalchman, M., Moss, J., \& Case R. (2001). Psychological models for the mathematical understanding: Rational numbers and functions. In S.M. Carvers, \& D. Klahr (Eds.) Cognition and instruction: Twenty-five years of progress (pp. 1-39). Mahwah, NJ: Lawrence Erlbaum Associates.

Kaminski, E. (1997). Teacher education students' number sense: Initial explorations. Mathematics Education Research Journal, 9(2), 225-235. http://dx.doi. org/10.1007/BF03217312

Kavishe, D. (2013, 08 February). Better teachers, better learners. Namibia Economist. Available from http://www.economist.com.na/25-education/2600-better-teachersbetter-learners

Kilpatrick, J., Swafford, J., \& Findell, B. (2001). Adding it up: Helping children learn mathematics. Washington, DC: National Academy Press.

Links, F. (2010). Namibia's skills deficits: Cross-sectoral perspectives and experiences. Windhoek: Namibian Employers' Federation.

Ma, L. (1999). Knowing and teaching elementary mathematics: teachers' understanding of fundamental mathematics in China and the United States. Mahwah, NJ: Lawrence Erlbaum Associates.

Markovits, Z., \& Sowder, J.T. (1994). Developing number sense: an intervention study in grade 7. Journal for Research in Mathematics Education, 25(1), 16-32. http:// dx.doi.org/10.2307/749290

McAnallen, R.R. (2010). Examining maths anxiety in elementary classroom teachers. Unpublished doctoral dissertation. University of Connecticut, Storrs, CT, United States.

McIntosh, A., Reys, B.J., \& Reys, R.E. (1992). A proposed framework for examining basic number sense. For the Learning of Mathematics, 12(3), 2-8.

National Council of Teachers of Mathematics. (1991). Professional standards for teaching mathematics. Reston, VA: NCTM. Available from http://www.nctm.org/ standards/content. aspx?id=26863

National Council of Teachers of Mathematics. (2000). Curriculum and evaluation standards for school mathematics. Reston, VA: NCTM.

Reubens, A. (2009). Early Grade Mathematics Assessment (EGMA): A conceptual framework based on mathematics skills development in children. Research framework based on mathematics skills development in children. Research Triangle Park, NC: United States Agency for Internation
from http://pdf.usaid.gov/pdf_docs/PNADS439.pdf

Reys, B.J., Barger, R., Dougherty, B., Hope, J., Lembke, L., Markovits, Z., et al. (1992). Developing number sense in the middle grades. Reston, VA: NCTM. http://dx.doi. org/10.2307/749900

Reys, R., Reys, B., Mclntosh, A. Emanuelsson, G., \& Yang, DC. (1999). Assessing number sense of students in Australia, Sweden, Taiwan, and the United States. School Science and Mathematics, 99(2), 61-70.

Reys, R., \& Yang, D.C. (1998). Relationship between computational performance and number sense among sixth and eighth-grade students in Taiwan. Journal for Research in Mathematics Education, 29(2), 255-268. http://dx.doi. org/10.1111/j.1949-8594.1999.tb17449.x

Sowder, J., \& Schappelle B. (Eds.) (1989). Establishing foundation for research on number sense and related topics: Report of a conference (pp. 1-5). San Diego, CA San Diego University, Center for Research in Mathematics and Science Education.

Sowder, J.T., \& Wheeler, M.M. (1989). The development and concepts used in computational estimation. Journal for Research in Mathematics Education, 20(2) 130-146. http://dx.doi.org/10.2307/749278

Spaull, N. (2011). Primary school performance in Botswana, Mozambique, Namibia and South Africa. Paris: Southern African Consortium for Monitoring Education Quality (SACMEQ). Available from http://www.sacmeq.org/downloads/ Working\%20Papers/08_Comparison_Final_180ct2011.pdf

SPSS. (2009). PASW Statistics for Windows, Version 18.0 [computer software]. Chicago, IL: SPSS Inc. Available from http://www.spss.com

Trafton, P. (1989). Reflections on the number sense conference. In J.T. Sowder, \& B.P. Schapelle (Eds.), Establishing foundation for research on number sense and B.P. Schapelle (Eds.), Establishing foundation for research on number sense and
related topics: Report of a conference (pp. 74-77). San Diego, CA: San Diego related topics: Report of a conference (pp. 74-77). San Diego, CA:
University, Center for Research in Mathematics and Science Education.

Tsao, Y-L. (2004). Exploring the connections among number sense, mental computation performance and the written computation performance of elementary preservice teachers. Journal of College Teaching and Learning, 1(12), 71-90.

Tsao, Y-L. (2005). The number sense of pre-service elementary school teachers. College Student Journal, 39(4), 647-679.

Yang, D.C., Reys, R.E., \& Reys, B.J. (2009). Number sense strategies used by pre-service teachers in Taiwan. International Journal of Science and Mathematics Education 7(2), 383-403. http://dx.doi.org/10.1007/s10763-007-9124-5 